\title{
Wanda Pimentel e Gloria Goméz-Sanchéz: novos olhares sobre as produções de extração Pop de mulheres artistas na América do Sul (1960 e 1970)

\author{
Carolina Vieira Filippini Curi ${ }^{7}$
} \\ DOI 10.20396/eha.vil4.3477
}

O presente trabalho é parte integrante de um projeto de pesquisa de doutorado desenvolvido junto ao Programa de Pós-graduação em Artes Visuais do Instituto de Artes da Unicamp, em andamento, que visa a investigar as mulheres artistas de países da América do Sul que dialogaram com a visualidade Pop em suas produções durante as décadas de sessenta e setenta, com foco na compreensão das redes de contato e circuitos profissionais que apoiavam suas produções.

A Pop Art foi um dos mais importantes movimentos artísticos da segunda metade do século XX. Embora tenha sido largamente analisado, o movimento foi sempre estudado a partir de um foco na produção de um grupo de famosos artistas homens. Como destaca Sid Sachs, "mais do que qualquer movimento artístico pós-Segunda Cuerra Mundial, a Pop Art foi representada por dois punhados de pintores americanos e britânicos. Mulheres artistas apresentadas nas primeiras exposições Pop foram relegadas às margens da história."2 Com isso, as produções femininas que exploraram essa estética - mesmo aquelas que circularam amplamente nos anos 60 - não foram, no geral, incluídas nas publicações e exposições posteriores a respeito do movimento, nem nas pesquisas da história da arte que tratavam do tema. Isso se deu, em partes, devido a resistência de críticos e teóricos em ler produções femininas como Pop, pois consideravam o estilo cool e despersonalizado dos homens artistas americanos, e suas técnicas mecanizadas, como os critérios definidores da Pop. Além disso, a intervenção feminista na história da arte, responsável pela releitura de obras de artistas mulheres que se iniciou nos anos 70 , tomou como prioridade, na época, a crítica à misoginia e ao sexismo pornográfico presentes na arte e na cultura Pop como um todo, evitando, com isso, uma análise mais profunda das obras de artistas ligadas à essa estética. As

\footnotetext{
1 Doutoranda em Artes Visuais pelo Programa de Pós-Graduação em Artes Visuais da Universidade Estadual de Campinas (IA/UNICAMP), desenvolve a pesquisa "Circulações e redes de contato: artistas sul-americanas associadas a arte pop nas décadas de 1960 e 1970 " sob orientação da Profa. Dra. Claudia Valladão de Mattos Avolese, com auxilio da Coordenação de Aperfeiçoamento de Pessoal de Nível Superior (CAPES). Mestre em Estudos Curatoriais pela Universidade de Coimbra (Colégio das Artes/UC). Possui bacharelado em Comunicação Social pela Pontifícia Universidade Católica do Rio de Janeiro. carol.filippini@gmail.com

2 SACHS, 2010, p.18.
} 
mulheres artistas sul-americanas associadas à Pop foram, assim, duplamente negligenciadas, por serem mulheres e por produzirem fora do eixo Estados Unidos-Europa.

A história aceita da Pop, como destaca Kalliopi Minioudaki, foi organizada em torno de "assuntos masculinos e objetos femininos". ${ }^{3}$ O cânone do movimento "dependeu exclusivamente de artistas homens cuja iconografia muitas vezes objetificou as mulheres. No entanto, não só havia mulheres artistas da Pop, mas várias delas expressavam a subjetividade feminina de várias maneiras protofeministas". ${ }^{4} \mathrm{~A}$ análise das obras de artistas sul-americanas de visualidade Pop se faz importante, portanto, para trazer a tona a essa produção, para um entendimento de que existiram várias vertentes Pop, e para uma melhor compreensão das estratégias Pop adotadas fora do eixo Estados Unidos - Europa, especificamente em países da América do Sul. Como ressalta Rodrigo Alonso, a produção de estética Pop de países sul-americanos - que lidavam com a censura de governos militares ditatoriais, altas taxas de analfabetismo, recente expansão da televisão, entre outros possuiu características particulares. ${ }^{5}$

Recentemente, as produções de algumas artistas associadas a Pop foram retomadas em exposições e publicações que buscavam apresentar o movimento como um fenômeno não exclusivamente anglo-americano, mas como uma categoria global ${ }^{6}$, e também em mostras que tinham como tema a produção de mulheres artistas latino-americanas ${ }^{7}$. Nesse contexto, artistas como a brasileira Wanda Pimentel e peruana Gloria Gomez-Sanchez voltaram a receber atenção. Além de terem explorado a estética Pop nos anos 60, as artistas tem em comum o fato de representarem de maneira constante, em suas obras, a figura feminina, e discutirem a objetificação das mulheres e o papel das mesmas na sociedade da época.

O trabalho de Wanda Pimentel, nascida em 1943, no Rio de Janeiro, passou a receber especial atenção recentemente, em um contexto de reavaliações históricas da arte Pop e da produção feminina latino-americana, aparecendo em exposições como International Pop, com curadoria de Darsie Alexander e Bartholomew Ryan, realizada no Philadelphia Museum of Art, em 2016 e Radical Women: Latin American Art, 1960-1985, com curadoria de Cecilia Fajardo-Hill e Andrea Giunta, inau-

\footnotetext{
3 MINIOUDAKI, 2010, p.90.

4 MINIOUDAKI, 2010, .90.

5 C.f. ALONSO, Rodrigo. Un arte de contradicciones. In: ALONSO, Rodrigo. HERKENHOFF, Paulo. Arte de contradicciones. Pop, realismos y política. Brasil-Argentina 1960. Buenos Aires: PROA, 2012.

6 Como, por exemplo, as exposições The World Coes Pop, com curadoria de Jessica Morgan e Flavia Frigeri, na Tate Modern, em 2015, e International Pop, com curadoria de Darsie Alexander e Bartholomew Ryan, no Philadelphia Museum of Art, em 2016.

7 Como a exposição Radical Women: Latin American Art, 1960-1985, com curadoria de Cecilia Fajardo-Hill e Andrea Giunta, inaugurada em 2017 no Hammer Museum, exibida também na Pinacoteca de São Paulo em 2018.
} 
gurada em 2017 no Hammer Museum, exibida também na Pinacoteca de São Paulo em 2018. As obras produzidas por Pimentel nos anos 60 e 70 criticavam o mundo mecanizado e impessoal e os efeitos alienadores dos meios de comunicação de massa. Pimentel explorava, em suas obras, a estética da propaganda, utilizando cores fortes e chapadas, e discutia a posição dos indivíduos frente a mercantilização do mundo na sociedade moderna de consumo, retratando os espaços domésticos contaminados pelos objetos produzidos e publicizados em massa, o que indicaria sua conexão com a Pop Art. Com cores vibrantes, sem textura, sem pinceladas aparentes e com contornos bem delineados, suas obras traziam a tona, de acordo com Camila Bechelany, "os debates sobre a sociedade de consumo, as novas tecnologias e principalmente a postura mais reivindicativa da mulher moderna". ${ }^{8}$ Sua série Envolvimento, que recebeu esse nome por tratar da relação dos indivíduos com os objetos que os cercam, trazia, como destaca Daniela Labra, uma reflexão acerca da mulher já emancipada em uma sociedade consumista. As pinturas da série centravam-se na representação de objetos domésticos e de fragmentos do corpo feminino no ambiente doméstico e íntimo, como pode ser visto na tela Sem título, de 1968 (figura 1), na qual uma mulher é retratada de pé em cima da bancada da cozinha. Na obra, vemos as pernas e um dos pés de uma mulher pisando em uma pia onde vários objetos encontram-se espalhados, como talheres e copos. Vemos ainda pratos e taIheres em uma bandeja, um liquidificador e uma xícara fumegante com alguma bebida quente. No fogão, um bule transborda, e o líquido derramado parece começar a pingar para o chão. O pequeno caos que se instaura na cozinha enquanto a mulher pisa na bancada sem preocupar-se com o que acontece a sua volta, remeteria a uma nova postura em relação ao espaço e aos afazeres domésticos. A obra faz referência as transformações vividas pelas mulheres brancas de classe média na época, que começaram a ocupar outros espaços e a travar um embate com as tarefas de cuidar da casa e servir ao marido, até então atribuídas a elas.

Nas obras da série Envolvimento, Pimentel representa os fragmentos do corpo da mulher e os objetos apresentados em relação de igualdade, em um movimento que humaniza os objetos ao mesmo tempo que objetifica o corpo. Na sociedade de consumo, os objetos ocupam um novo patamar, enquanto o corpo fragmentado dessa mulher, cujo rosto nunca aparece, é apresentado como um produto. Como destaca Bechelany, "a fragmentação do corpo mutila a subjetividade da mulher e intensifica sua condição de objeto de desejo/doméstico/de uso do próprio corpo na pintura de Pi-

8 BECHELANY, 2017, P.65. 
mentel". ${ }^{9}$ Com a fragmentação operada, portanto, como afirma Lisete Lagnado, "o corpo perde sua integridade física para se tornar apenas uma montagem inorgânica de partes coisificadas a serem entregues, de forma servil, à cobiça de campanhas publicitárias." ${ }^{\circ 0}$ Em outras obras da série, como a pintura Sem título, de 1968 (figura 2), Pimentel aborda ainda essa objetificação ao mesclar o corpo feminino ao mobiliário da casa, com suas pernas sendo confundidas com as pernas das mesas, o corpo que cede quase à decoração e a reificação, uma mulher-objeto. As obras da série Envolvimento, assim, se relacionam com os embates de gênero do período, com a emergência de apontar para a grande clausura da mulher nas obrigações domésticas. "Aos olhos de hoje, contra o estigma da "mulher recatada", a obra ganha uma potência inesperada"."

Poderia se pleitear, como destaca Lagnado, que Pimentel é um exemplo raro de participação feminina no âmbito da arte Pop, um movimento repleto de símbolos masculinos. Porém, as obras da artista questionavam a objetificação da mulher não por meio de uma repetição ou celebração do mesmo, como parte das obras dos artistas norte-americanos, mas de uma fragmentação e de um quase apagamento desse corpo nas obras. Lagnado observa, ainda, que a produção da artista se diferencia da de outras artistas vinculadas ao movimento na época: "o ritmo seguido por Wanda Pimentel se distancia da tática dos happenings de importantes mulheres vinculadas à mais famosa vertente da pop". ${ }^{12}$ Apesar da longa carreira, das análises recentes de sua produção, e de sua participação em algumas exposições emblemáticas, a obra de Pimentel permanece, em partes, desconhecida, mesmo nacionalmente.

O trabalho da peruana Gloria Gómez-Sánchez também a voltou a ganhar algum reconhecimento recentemente, participando de exposições como a já citada Radical Women: Latin American Art, 1960-1985, depois de ficar fora do circuito de arte por quase quarenta anos. Nascida em 1921, em Lima, Gómez-Sánchez - considerada uma das mais inovadoras e subversivas artistas peruanas de sua geração - produziu diversas obras de estética Pop no final da década de 60, como parte do Grupo Arte Nuevo. Seus trabalhos de vertente Pop, em sua maioria centrados na representação da figurava feminina, lidavam com a hiperproliferação de imagens, com a crescente onipresença da televisão, e discutiam a objetificação da mulher e as noções aceitas de feminilidade. Como relata Dorota Biczel, "por volta de 1967, Gómez-Sánchez se voltou para superfícies achatadas, uma abor-

\footnotetext{
9 BECHELANY, 2017, p.70.

10 LAGNADO, 2017, p.50.

11 LAGNADO, 2017, p.48.

12 ibid., p.49.
} 


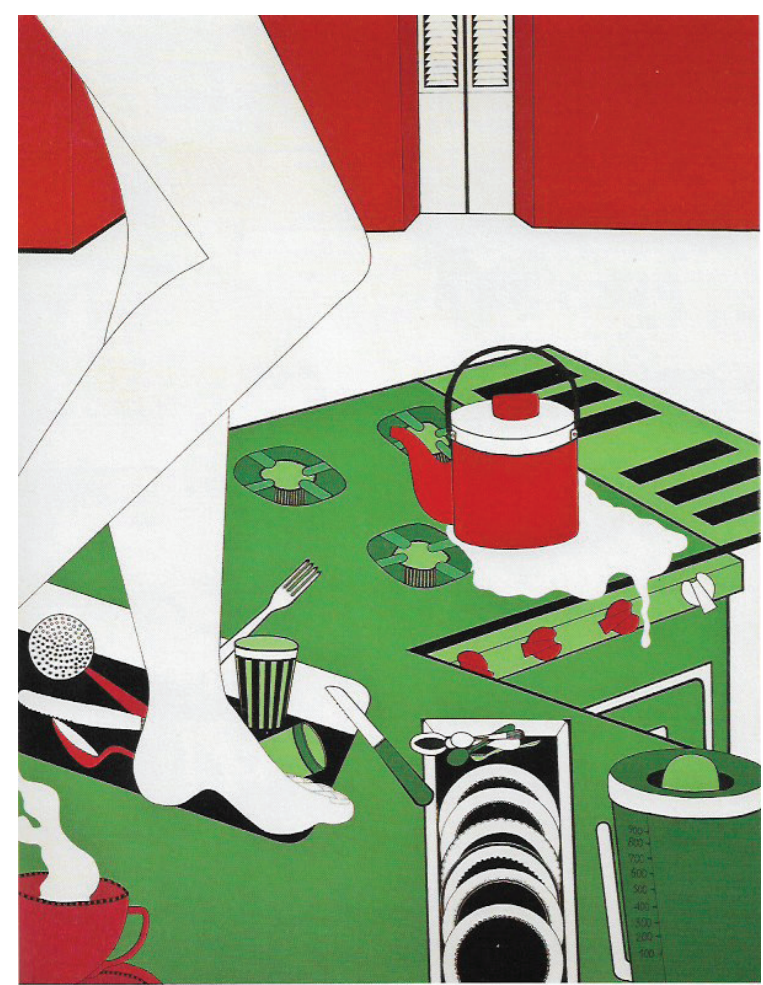

[Figura 01] Wanda Pimentel, Sem título, da série Envolvimento, 1968.

Vinílica sobre tela, 130 × 98 cm, Coleção Hecilda e Sérgio Fadel, Rio de Janeiro.

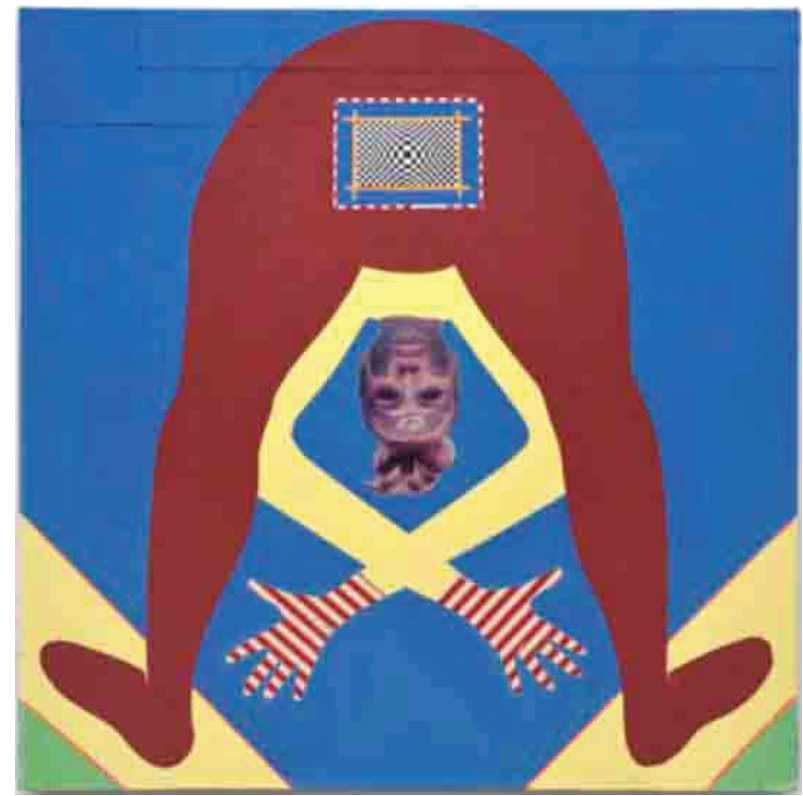

[Figura 03] Gloria Gómez-Sánchez, Guante rayado, 1968 (recuperada e reconstruída em 2014)

Pintura e colagem sobre nórdex, $122 \times 122 \mathrm{~cm}$.

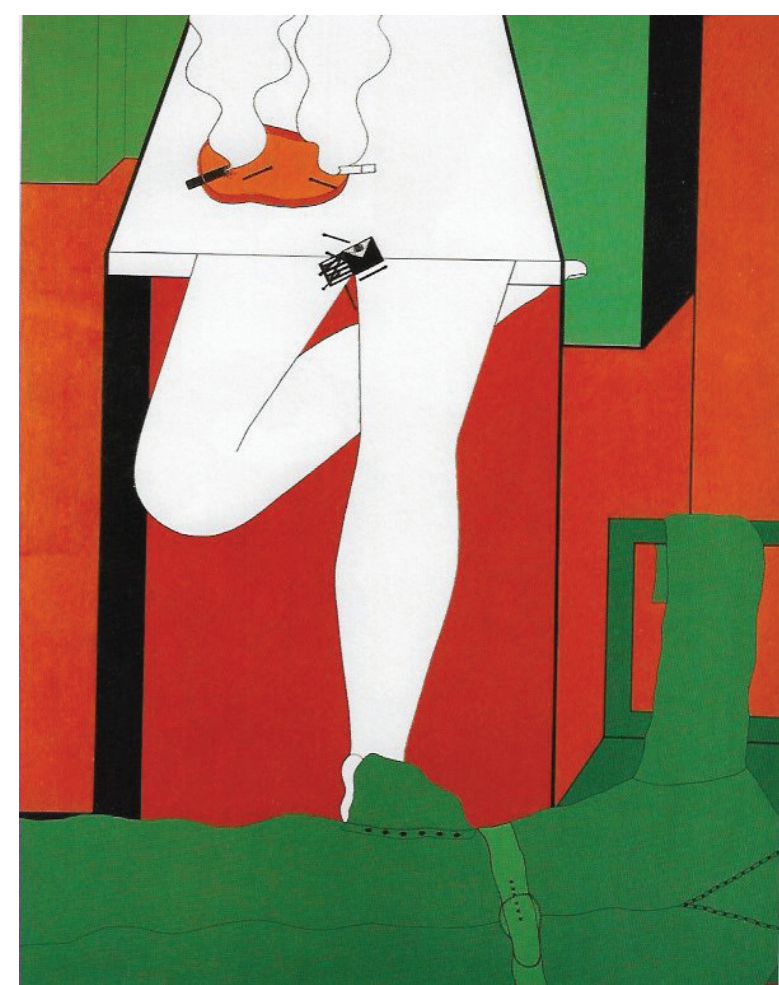

[Figura 02] Wanda Pimentel, Sem título, da série Envolvimento, 1968

Vinílica sobre tela, 146 × 114 cm, Coleção particular, Rio de Janeiro.

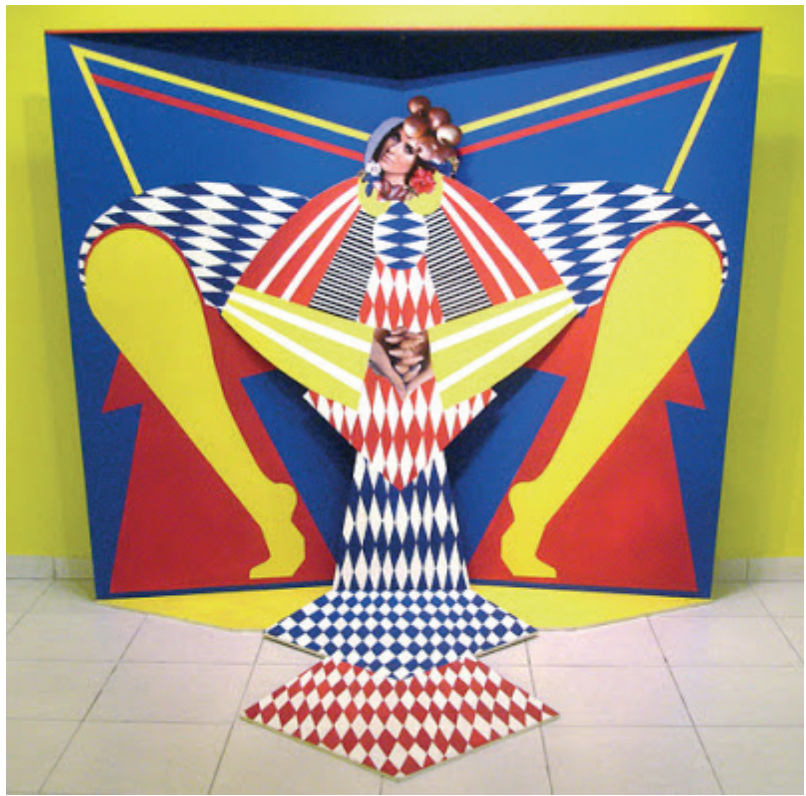

[Figura 04] Gloria Gómez-Sánchez, Corbata, 1968 (reconstruída em 2007-2014)

Pintura e colagem sobre madeira, $210 \times 250 \times 50 \mathrm{~cm}$. "Diapositiva y fotografia de Corbata" (ca. 1968) Archivo GCS. 
dagem gráfica a partir de cores e padrões, com uma paleta em geral limitada as cores primárias e figuras femininas com faces recortadas de revistas de celebridades". ${ }^{13}$ Para a autora, essas "características evocativas da Pop art resultavam em composições distorcidas e sexualmente provocativas das mulheres". ${ }^{14}$ Já para Emilio Tarazona, Goméz-Sánchez foi pioneira na discussão de gênero na cena artística do país. As obras da artista inauguraram uma perspectiva de gênero bastante inédita até aquele momento na cena peruana.

Uma linguagem que assimila rapidamente procedimentos da Pop Art, da Op Art e superfícies planas de cores intensas, como veículos para exibir um conjunto de representações femininas que foram em grande medida retiradas da publicidade. ${ }^{15}$

Tanto a incorporação da Pop quanto a preocupação com a discussão a respeito do preconceito de gênero e da objetificação da figura feminina podem ser vistas em obras como a intitulada Guante Rayado, de 1968 (figura 3). A mulher, retratada em cores fortes, de costas, usando roupas apertadas em vermelho e amarelo, está em uma posição flexionada, com a cabeça aparecendo entre as pernas, os braços cruzados e as mãos esticadas, usando luvas listradas. O rosto da mulher, nesta obra e em diversas outras, é representado com fotos de modelos recortadas de revistas dos anos 50 e 60, nas quais os papéis de gênero permaneciam fortemente acentuados. O retângulo com efeito ótico ao mesmo tempo que simula um orifício anal, dando destaque a ele, também remete ironicamente a uma tarja de censura, ou a um alvo, elemento utilizado em outras obras da artista. A mulher, em uma posição invertida, que dá destaque a região do orifício anal, posiciona os braços em forma de $x$, semelhante a um gesto de pare, como que reivindicando contra a própria objetificação. Em Corbata, de 1968 (figura 4), construída em um grande painel de madeira pintado com cores primárias, que se assemelha a um livro pop-up aberto, é representada uma figura feminina de pernas abertas, sentada em uma espécie de cadeira ou trono, usando uma gravata. Corbata é um dos primeiros trabalhos de Gómez-Sánchez a confrontar explicitamente a questão da objetificação feminina e das relações de poder relacionadas a feminilidade e a masculinidade. As mãos entrelaçadas entre as pernas, também recortadas de uma revista, remetem a chamada vagina dentada, a lenda da vagina castradora que revelava o pavor dos homens frente ao que buscavam reprimir, jogando, assim, com mitos relacionados a feminilidade, ao mesmo tempo que discutia como a postura da mulher

\footnotetext{
BICZEL, 2018, p.329.

ibidem.

5 TARAZONA, 2015, p.45.
} 
moderna era vista por muitos como uma ameaça. A estampa e o design da roupa da mulher remetem ao traje do arlequim, personagem da Commedia dell'Arte que era servil, porém astuto. Na obra, a mulher fantasiada de arlequin ocupa o trono destinado ao rei, ou ao homem, afirmando-se como igual, desafiando posições previamente estabelecidas. A gravata, o elemento de maior destaque da obra, sai do painel para o espaço. Um símbolo normalmente atribuído a masculinidade, aparece aqui como parte do traje feminino. A gravata poderia sugerir a modificação da posição feminina em um país conservador e católico como o Peru, onde o lugar das mulheres era amplamente limitado ao domínio doméstico. Como ressalta Sofia Gotti, "a mulher em seu trabalho celebra seu novo papel com audácia e ousadia, desconsiderando as críticas (....) Corbata, de Gómez, satura o corpo feminino com símbolos e referências ao ponto em que ele se transforma em uma paródia crítica de si mesmo". 16

Coméz-Sanchez produziu, portanto, durante a década de 1960, diversas obras de estética Pop, com referencia a imagens da mídia, de forma semelhante aos artistas Pop norte-americanos e ingleses. Ao mesmo tempo, como ressalta Cotti, embora os trabalhos de Comez-Sanchez e de outros artista peruanos da época discutissem os efeitos dos meios de comunicação de massa e dos produtos importados produzidos em massa em sua identidade nacional, o que justifica em grande parte sua afiliação ao Pop, eles tratavam os objetos de consumo e de contemplação de uma maneira diversa da maior parte dos artistas da Pop norte-americana e inglesa. Isso poderia ser visto nas obras de Comez-Sanchez, que evidenciavam a tensão entre o efeito alienador da cultura de consumo e um papel atribuído às mulheres dentro de um patriarcado peruano tipicamente católico, criticando a objetificação do corpo feminino não por meio de uma repetição ou celebração do mesmo, mas da representação de um corpo contorcido, um tanto desconstruído, quase fragmentado, forçado a ser visualmente atraente através de sua escravização pela mídia. Em 1975, Gómez-Sánchez abandonou sua carreira nas artes visuais, e quase nenhum de seus trabalhos sobreviveu. Apesar da recentemente retomada de sua produção, a artista continua tendo pouca repercussão, mesmo no Peru, e boa parte dos especialistas da área desconhecem seu trabalho.

A análise das obras dessas artistas - assim como de outras artistas associadas a arte Pop na América do Sul nas décadas de 1960 e 1970 - se faz importante, portanto, não apenas para recuperar essas obras e hermenêuticas negligenciadas, mas para propor novas possibilidades de leitura para essas produções e até mesmo para o próprio movimento Pop. A produção e a própria trajetória

16 GOTTI, 2016, p. 277. 
dessas artistas refutam a ideia de que, no contexto da Pop, a figura feminina teria ocupado o lugar apenas de objeto passivo. Diversas artistas dos anos 60 não só exploraram a estética Pop, mas a utilizaram para criticar a objetificação e fetichização do corpo feminino e para questionar noções aceitas de feminilidade. Além disso, a análise dessas produções permite um alargamento do entendimento da visualidade Pop, trazendo uma visão historicamente mais precisa. Diversos elementos encontrados na produção dessas artistas fazem um contraponto a imagem canônica da Pop, como o uso de técnicas manuais, a crítica da objetificação feita não por meio da repetição e do excesso, mas do apagamento ou da fragmentação das figuras, a valorização de objetos únicos em contraponto a ideia de serialidade, a referência ao corpo das próprias artistas como contraponto a uma atitude despersonalizada, entre outros.

É, em suma, a ideia da própria Pop Art que deve ser reavaliada em face a todos os recém descobertos trabalhos de mulheres artistas. (...) muitas mulheres artistas Pop nos forçam a reconfigurar os contornos intelectuais do próprio movimento Pop Art, pois incluí-las dá à Pop uma inflexão muito diferente e mais historicamente precisa do que quando foi construída como um movimento "somente para homens" além disso, nos faz pensar diferentemente sobre o trabalho inicial de algumas artistas (...), que encontram um lugar apropriado dentro de uma versão expandida da Pop Art." ${ }^{m 7}$

17 NOCHLIN, 2010, p.15. 


\section{Referências bibliográficas:}

ALONSO, Rodrigo. Un arte de contradicciones. In: ALONSO, Rodrigo. HERKENHOFF, Paulo. Arte de contradicciones. Pop, realismos y política. Brasil - Argentina 1960. Buenos Aires: PROA, 2012.

BECHELANY, Camila. "A vida dos objetos: a série Envolvimento de Wanda Pimentel", p.70. In: PEDROSA, Adriano \& BECHELANY, Camila. Wanda Pimentel: envolvimentos. São Paulo: MASP, 2017.

BICZEL, Dorota. "Gloria Gómez-Sánchez", p.329. In: FAJARDO-HILL, Cecilia \& GIUNTA, Andrea. Mulheres Radicais: arte latino-americana, 1965-1980. São Paulo: Pinacoteca de São Paulo, 2018.

COTTI, Sofia. Expanded Pop: Politics, Popular Culture and Art in Argentina, Brazil and Peru, 1960s. Londres: Chelsea College of arts and Design, 2016, p. 277.

LAGNADO, Lisette. "Desordem e erotismo em Wanda Pimentel", p.48. In: PEDROSA, Adriano \& BECHELANY, Camila. Wanda Pimentel: envolvimentos. São Paulo: MASP, 2017.

MINIOUDAKI, Kalliopi. Pop proto-feminisms: beyond the paradox of the women pop artist. In: SACHS, Sid; MINIOUDAKI, Kalliopi. Seductive Subversion: Women Pop Artists, 1958-1968. Nova lorque: Abbeville Press, 2010.

NOCHLIN, Linda. "Running on empty: women, pop and the society of consumption", p.15. In: SACHS, Sid \& MINIOUDAKI, Kalliopi. Seductive Subversion: Women Pop Artists, 1958-1968. New York: Abbeville Press, 2010.

SACHS, Sid. Beyond the surface: women and pop art 1958-1968. In: SACHS, Sid; MINIOUDAKI, Kalliopi. Seductive Subversion: Women Pop Artists, 1958-1968. Nova lorque: Abbeville Press, 2010.

TARAZONA, Emilio. Gloria Cómez-Sánchez: una década de mutaciones (1960, 1970). Lima: Instituto Cultural Peruano Norteamericano, 2015, p.45. 